\title{
Rhodium-Catalyzed Enantioselective Hydroacylation of Ketones
}

Metal-Catalyzed Asymmetric Synthesis and Stereoselective

Reactions

\section{Key words}

rhodium

ketone hydroacylation

enantioselective

lactonization<smiles>O=CCOc1ccccc1C=O</smiles>

Selected examples:<smiles>O=C1O[C@H](c2ccccc2)COc2ccccc21</smiles>

$99 \%$

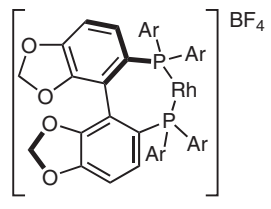

(5 mol\%)<smiles>CPC1COc2ccccc2C(=O)O1</smiles>

$85-99 \%$ 99 to $>99 \%$ ee<smiles>CC(=O)COc1ccccc1</smiles>

$0-9 \%$
Significance: A conceptually novel approach to enantioselective lactonization is presented based on a previously unknown $\mathrm{Rh}$-catalyzed $\mathrm{C}-\mathrm{H}$ bond activation and intramolecular hydroacylation of ketones. The phosphine ligand is crucial since increased phosphine basicities improved the selectivity of the product over the competing decarbonylation of starting material. Excellent yields and enantioselectivities are seen for a variety of aromatic and aliphatic ketones.
Comment: The intramolecular hydroacylation occurs with complete regiocontrol to form Tishchenko-type products instead of benzoin-type products. The present methodology is atom-economic and provides a great alternative to popular lactonization strategies such as the Yamaguchi macrolactonization.

Review: For a review on macrolactonizations, see: A. Parenty, X. Moreau, J.-M. Campagne Chem. Rev. 2006, 106, 911. 